\title{
The Current Situation and Reconsideration of Information Technology Education Goals in China's Rural Primary and Middle Schools
}

\author{
Sun Yan \\ Jilin Business and Technology College, Changchun, China \\ 619784966@qq.com
}

\begin{abstract}
Information technology education goals are the core element of information technology education. The appropriateness of the target determines the aptness of goal-directed function and evaluation function. This article is based on the significant differences of dualistic urban and rural areas in social status, to reflect the rationality of the homogenization of the rural information technology education goal in the current urban and rural, and try to build a separate information technology goals in rural elementary and middle schools.

Index Terms - Use "keywords" style here
\end{abstract}

\section{Implementation Status of Information Technology Education in Rural Primary and Middle Schools in China}

Northeast Normal University "Underdeveloped Regions in Rural Basic Education Information Technology Promote Strategy Research" research group made a sample survey of 80 schools which selected from eight provinces/autonomous regions.[1]As a whole, information literacy of rural junior high school students is unable to achieve the objectives of information technology education level required.

\subsection{The rural information technology education is lack of a good social support}

The overall data analysis shows that overall rural school education information technology process, which is under "The Rural Elementary and Middle Schools Modern Distance Education Project" and "School to School Project", has been moving forward in underdeveloped regions, but there are some major problems in the perspective of demand, which performance in: (a) School of education information technology infrastructure and the construction of resource demands are still strong, $95.8 \%$ of the principal think school computer needs to increase the quantity. The main difficulty, which exists in more than $80 \%$ schools, is the lack of the necessary funds in the information technology of equipment maintenance and software resources construction. (b)Rural schools have the huge demand in external support of education information technology, but the original training didn't play a proper role. So supervision and evaluation of consciousness to the village primary school education information technology work is relatively weak. The interactive relationship between the rural school and community information technology has gained attention and establishment of interactive activities, but it is still relatively small and its form is single.

\subsection{It is very outstanding that rural information technology education}

Teachers are the key factors to measure the status of implementation of educational objectives. Our survey found that there are several aspects of the problem in current rural primary and secondary school teachers : (a) The number of professional teachers is shortage(b)Teachers' specialization degree is not high (c)Teacher training is insufficient. The analysis of the data shows only more than half of the information technology teachers think that they can do teaching work and some teachers think that they can be competent for the job through trained. At the same time, most of information technology teachers think they are unable to do teaching work in rural primary school. In addition, information technology teachers in rural schools have obvious shortcomings in the subject teaching ability, information resources and development ability. The information technology teacher training work and the teacher's professional development is not ideal in the underdeveloped regions. On the other hand, it also suggests department of education did not pay enough attention to the development of information technology ability of rural schools teachers, especially to rural primary schools.

\subsection{Lack of information software resources and idle}

Lack of hardware facilities matching software resources is an important factor which affects effective implementation of rural information technology education. It was found that the software resources construction of rural primary and secondary schools need to be solved problems in sampling survey ----CD and other supporting resources development and cyber source development and construction is the main problem in the school of software resource construction. It is an average of $60.9 \%$ schools which need to solve the disc supporting the resource problem mainly, and it is an average of $52.2 \%$ schools which need to solve network resources development and construction. In addition, from various schools, there are only $25 \%$ village primary schools which need development and construction of network resources that is far lower than that of other schools, while the township primary school and primary school in the demand has reached $68.8 \%$ and $53.8 \%$.Thus, the hardware construction of network construction is relatively backward in the village primary school where the demand for network resources is very low accordingly. 
1.4 Differences in students' learning experience and information congenital absence of capital

Learning experience is what learners have about learning and life background and future learning condition. Due to difference in living environment between urban and rural students makes learning experience must be different. Students in rural areas has the congenital disadvantage in learning content of city-oriented; in the learning conditions, there is a long gap between rural students and urban students level of information environment, especially the closed school management system makes that they rarely come into contact with information technology equipment after school which can not be guaranteed after-school extension. Another obstacle is the reality of rural students' congenital absence of information technology capital.

\section{The Reconstruction of Concepts and Principles}

\subsection{The core principle is to cultivate and enhance information literacy}

No matter what is the difference between urban and rural information technology education target system, the cultivation and promotion information literacy of the ultimate goal will not change. During the goal of reconstruction, it weakened the demand for skill levels but compensate for the other two areas from cognition, emotion and attitude so as to achieve the overall level of the information literacy of ascension.

\subsection{The principle of three-dimensional target system}

Structured hierarchical specific target system refers to target system on the transverse divided into cognitive domains, attitudes and emotional areas, skill areas. Skill area is divided in the longitudinal direction for the technical understanding, basic operations, technology, simple application, comprehensive application of technology and the use of technology for problem solving, etc. multiple levels. Detailed information technology goals in each period achieve the goal of a process that reduced the gradient at all levels and provided the rural schools with appropriate "tolerance", which is good for the selection and operation more flexible.

\subsection{The principle of combining classification positioning and selective}

States should formulate a set of rural basic education information performance evaluation system. First, investigate the school facilities allocation, strength and level of teachers and students, such as the basis of the achieved level. Then, choose suit oneself scientifically school conditions and the status of the goals system, the school also can choose the next level after the goal achieved through evaluation to ensure its implementation has been the most appropriate goals.

\section{Reconstruction of China's Rural Primary and Secondary Information Technology Education Goals}

Although the implementation of the rural educational goals is a separate IT system, the overall objective of urban and rural information technology education still is the same --- cultivate and improve the students' information literacy.
Cultivating and improving the students' information literacy is still the core of the reconstruction of information technology education target system.

\subsection{The problems existing in the rural primary and middle school students' information literacy training}

The study found that there are two main aspects problems in our rural elementary and middle school students information literacy at present, one is that Compared with urban students, the overall level of the countryside student information literacy is more backward; the other is that the structural of rural students information literacy is imbalance. Imbalance in the structure of the main performance is: information skill level knowledge is relatively good; emotional level, the lack of basic information ethics knowledge; knowledge level, master the content is limited. Compared with urban students, rural students have relatively poor grasp of information skill level; in information literacy constitute two other aspects of rural students are more vulnerable.

\subsection{The reconstructed object classification system}

We think that we can solve the existing problems by the latitude and level which divided from reconstruction of rural elementary and middle schools information technology education target system. We can play a guiding and encouraging function target really so as to improve the overall level of the rural students' information literacy. In order to make reconstruction of the target system more operational, we adopted Bloom's taxonomy of educational objectives of "knowledge, attitude and emotion, skill" method, then we divided Information literacy on the target level into about information knowledge, knowledge of the skills and knowledge about emotional three areas.[2]

\subsection{Differences between the reconstruction and the original target system}

First of all, it has adjusted the division of the target latitude. According to the actual target system, in order to facilitate rural schools according to their actual flexibility to select and operate, we adopt the goal of this article system partition method. Second, the content of the skill areas are divided into more and more detailed level.

In the field of cognition and attitude, emotion, we have the same requirements of urban and rural areas, but we made some adjustments in the skill field. We have set up a series of goals between the existing level of rural and reached the goals and combined with the existing support conditions to add some level according to some areas where do not have conditions. In order to make the implementation of the target is more feasible, we started from primary stage goals to achieve the ultimate goal step by step.

Third, compile teaching materials according to the different level of rural schools and evaluate.

As there is big difference between conditions vary widely among rural schools rural schools which have different starting points, realizing the same goal system is not conducive to the development of some school. The target system can guide the rural schools to choose what is suitable 
for their own level according to their actual condition. The evaluation is also more operational if they can accord with its choice to evaluate. Thus it can ensure each school and each student progress on the basis of the original. With gradually narrowing the gap between urban and rural areas, it will ultimately end up the same between urban and rural areas although we are in pursuit of development under difference at present.

\section{References}

[1] Northeast Normal University. Ministry of Education Humanities and Social Sciences Key Research Base of Major Projects "Basic Education
Above all, establishing information technology education target system scientifically can provide basic premise and guarantee the effective implementation of information technology education. It is just a basic idea for information technology education in rural primary and secondary schools target system which needs further study on a more detailed classification.

in Underdeveloped Rural Areas Information Promotion Strategy" Total Research (R). 2009

[2] Bloom Education Objective Taxonomy. East China Normal University Press.1998. 